\title{
The direct costs of treating human visceral leishmaniasis in Brazil
}

\author{
Tália Santana Machado de Assis[1],[2], Dian Carlos Pinheiro Rosa ${ }^{[1]}$, \\ Eliane de Morais Teixeira ${ }^{[1]}$, Gláucia Cota ${ }^{[1]}$, André Luís Ferreira Azeredo-da-Silva ${ }^{[3],[4]}$, \\ Guilherme Werneck ${ }^{[5]}$ and Ana Rabello ${ }^{[1]}$
}

\begin{abstract}
[1]. Grupo de Pesquisa: Pesquisa Clínica e Políticas Públicas em Doenças Infecciosas e Parasitárias, Centro de Pesquisas René Rachou, Fundação Oswaldo Cruz, Belo Horizonte, MG, Brasil. [2] Centro Federal de Educação Tecnológica de Minas Gerais, Campus Contagem, Contagem, MG, Brasil. [3] Instituto de Avaliação de Tecnologia em Saúde, Porto Alegre, RS, Brasil. [4] Universidade Federal do Rio Grande do Sul, Porto Alegre, RS, Brasil.

[5] Instituto de Medicina Social, Universidade do Estado do Rio de Janeiro, Rio de Janeiro, RJ, Brasil.
\end{abstract}

\begin{abstract}
Introduction: The drugs available for visceral leishmaniasis (VL) treatment in Brazil have specific characteristics in terms of operability, effectiveness, toxicity, and cost. The aim of this study was to estimate the direct costs of therapies recommended by the Ministry of Health (MH) for VL treatment in Brazil. Methods: The analytical perspective used was that adopted by the Brazilian Public Health System. Three drugs and four regimens were included: 1) N-methyl glucamine antimoniate intramuscularly at 20mg per kg per day for 30 days; 2) N-methyl glucamine antimoniate intravenously at 20mg per kg per day for 30 days; 3) amphotericin B deoxycholate at $1 \mathrm{mg}$ per $\mathrm{kg}$ per day for 21 days; and 4) liposomal amphotericin B at $3 \mathrm{mg}$ per $\mathrm{kg}$ per day for a 7 days treatment. Results: The estimated direct costs of treatment for an adult patient using N-methylglucamine antimoniate administered via the intramuscular and intravenous routes were USD 418.52 and USD 669.40, respectively. The estimated cost of treatment with amphotericin B deoxycholate was USD 1,522.70. Finally, the estimated costs of treatment with liposomal amphotericin B were USD 659.79, and USD 11,559.15 using the price adopted by the WHO and the Drug Regulation Board, respectively. Conclusions: This analysis indicates the economic feasibility of replacing N-methyl glucamine antimoniate with liposomal amphotericin $\mathrm{B}$, which allows a shorter treatment period with less toxicity compared with other treatments, provided that the purchase value used by the $\mathrm{WHO}$ and transferred to the $\mathrm{MH}$ is maintained.
\end{abstract}

Keywords: Therapeutics. Costs. Cost analysis. Visceral leishmaniasis.

\section{INTRODUCTION}

Visceral leishmaniasis (VL) is a severe human parasitic disease with a complex clinical course, and is often fatal if not diagnosed and treated ${ }^{1}$. In Brazil, 26,112 VL cases and 1,599 deaths were registered between 2007 and 2013, which corresponds to a mortality rate of $6.1 \%{ }^{2}$. This high number of deaths is to some extent correlated with the prescription of hightoxicity drugs for treatment ${ }^{3}$ as well as the inability of health care services to detect, diagnose, and provide early treatment for VL.

In Brazil, the Ministry of Health (MH) recommends the following drugs for VL treatment: N-methylglucamine antimoniate, amphotericin B deoxycholate, and liposomal amphotericin B. N-methylglucamine antimoniate has an efficacy of $83.1-96.9 \% \%^{4-7}$, and is recommended as the first-line

Corresponding author: Dra. Tália Santana Machado de Assis.

e-mail: talia@cpqrr.fiocruz.br

Received 7 April 2017

Accepted 19 June 2017 treatment for VL, despite its recognized toxicity ${ }^{8}$. Amphotericin $\mathrm{B}$ deoxycholate, which is the second choice for the VL treatment is also highly toxic. Its estimated efficacy ranges from 85.0$90.0 \%{ }^{8,9}$. Romero et al. ${ }^{6}$ conducted a randomized clinical study trial in Brazil and observed high toxicity in patients treated with amphotericin B deoxycholate, which led to the discontinuation of that arm of the study. Liposomal amphotericin B is indicated for patients with severe disease, those presenting comorbidities or immunodeficiencies, pregnant women, and those with renal or cardiac toxicity caused by the first- and second-line VL drugs ${ }^{10}$. Liposomal amphotericin B has strong leishmanicidal activity, and its estimated efficacy varies between $62.0-91.2 \%{ }^{6,11}$.

In Brazil, N-methylglucamine antimoniate and amphotericin B deoxycholate are produced in Brazil by Sanofi and Cristália, and are marketed under the names Glucantime ${ }^{\circledR}$ and Anforicin $\mathrm{B}^{\circledR}$, respectively. In contrast with the other drugs, liposomal amphotericin B (AmBisome ${ }^{\circledR}$ ) is produced in the United States, and its patent is pending, making it very expensive: United States Dollars (USD) 11,239.36 to treat an adult patient, when considering the price value adopted by the Drug Regulation Board [Câmara de Regulação de Medicamentos (CMED)] of 
the National Health Surveillance Agency [Agência Nacional de Vigilância Sanitária (ANVISA)] ${ }^{12}$. To increase access to this drug, the World Health Organization (WHO) established an agreement with the manufacturer Gilead Sciences, $\mathrm{Inc}^{13}$, in January 2010 to ensure a significant reduction in the price of the drug in countries where VL was endemic. This cost reduction allowed the drug to be incorporated into the Public Health System in Brazil.

To date, the drugs available for VL treatment in Brazil are administered via the intravenous and intramuscular routes. Because of their toxicity, specific tests must be performed during treatment to monitor liver, kidney, pancreas, and heart functions ${ }^{10}$. Although each treatment regimen has specific characteristics in terms of its operability, effectiveness, toxicity, and cost, no economic study of these factors has been conducted in Brazil. However, economic evaluations can help strengthen decision-making among health managers by promoting improved allocation of the limited resources ${ }^{14}$. Therefore, the objective of this study was to estimate the direct costs of therapies recommended by the $\mathrm{MH}$ for the treatment of patients with VL in Brazil.

\section{METHODS}

The analytical perspective used in this study was that adopted by the Sistema Único de Saúde(SUS), i.e., the payers' perspective. This perspective considers direct costs, which include the costs of all goods, services, and other resources used for to provide an intervention. This study included three drugs and four treatment regimens listed in the $\mathrm{MH}$ recommendations for VL treatment: 1) $\mathrm{N}$-methylglucamine antimoniate administered intramuscularly in outpatient settings $-20 \mathrm{mg}$ per $\mathrm{kg}$ per day for a 30 days treatment; 2) N-methylglucamine antimoniate administered intravenously in outpatient services $-20 \mathrm{mg}$ per $\mathrm{kg}$ per day for a 30 -days treatment; 3) amphotericin B deoxycholate administered at the hospital - 1mg per kg per day for a 21- day treatment; and 4) liposomal amphotericin B administered in-hospital-3mg per $\mathrm{kg}$ per day for a 7-day treatment.

The direct costs of all the evaluated therapeutic regimens were initially estimated using the micro-cost method, a costmeasurement technique that allows the detailed analysis of several variables, including the costs of drugs, the remuneration of health professionals, consumables, personal protective equipment, and complementary tests. Subsequently, the estimated costs were compared with the cost of treatment using the amount that the Public Health System reimbursed to public services.

The source used to estimate treatment costs was the Table of Current Prices from CMED/ANVISA ${ }^{12}$. The cost of therapy with liposomal amphotericin $\mathrm{B}$ was also estimated using the values adopted by the $\mathrm{WHO}^{13}$ and transferred to $\mathrm{MH}$. Moreover, we used Law 10,898 from December 30, 2015, of the municipality of Belo Horizonte, Minas Gerais, Brazil to calculate the remuneration for health care professionals; consequently, the monthly salary for a 40-hour work week was USD $2,806.37$ for a physician, USD 1,257.27 for a nurse, and USD 564.55 for a nursing technician ${ }^{15}$.
The time spent on health care services for treatment with: intramuscular N-methylglucamine antimoniate was 240 minutes in medical appointments +690 minutes receiving nursing technician assistance +690 minutes receiving nurses assistance; intravenous $\mathrm{N}$-methylglucamine antimoniate was 240 minutes in medical appointments $+1,290$ minutes receiving nursing technician assistance $+1,290$ minutes receiving nurses assistance; amphotericin B deoxycholate was 200 minutes in medical appointments $+6,370$ minutes receiving nursing technician assistance $+6,370$ minutes receiving nurses assistance; liposomal amphotericin B was 120 minutes in medical appointments $+1,290$ minutes receiving nursing technician assistance $+1,290$ minutes receiving nurses assistance.

The Pricing Database of the MH was used to determine the cost of consumables and personal protective equipment. The table of Procedures, Drugs, Prostheses, and Special Material of the Public Health System ${ }^{16}$ for the reimbursement of services paid by the SUS (for the treatment of diseases caused by protozoa) was used to calculate the cost of the tests used for the routine monitoring of treatment toxicity. This was conducted following the recommendations in the guidelines of the $\mathrm{MH}^{10,17}$ and the Reference Center for Leishmaniasis of Centro de Pesquisas René Rachou (CPqRR), Oswaldo Cruz Foundation, as detailed below:

N-methylglucamine antimoniate: urea and creatinine, $2 \times$ per week; electrocardiogram, blood count, alkaline phosphatase, aspartate transaminase, alanine transaminase, gammaglutamyltransferase, amylase, bilirubin, albumin, and lipase, $1 \times$ per week. Amphotericin B deoxycholate and liposomal amphotericin B: urea, potassium, magnesium, and creatinine, $2 \times$ per week; blood test, $1 \times$ per week. All costs were estimated in 2015 and refer to the treatment of a $60 \mathrm{~kg}$ patient. All costs were originally estimated in Brazilian currency, the Real (R\$), and were subsequently converted into USD ( 1 USD $=3.13 \mathrm{R} \$$ on 13 July 2015).

\section{RESULTS}

The estimated direct costs of treating a patient with VL using $\mathrm{N}$-methylglucamine antimoniate administered via the intramuscular and intravenous routes were USD 418.54 and USD 669.40 , respectively. The difference corresponds to the higher costs of remuneration for nursing technicians and nurses, and the price of consumables when medication was administered intravenously. The estimated direct cost of treatment with amphotericin B deoxycholate was USD 1,522.70. Finally, the estimated direct costs of therapy with liposomal amphotericin B were USD 11,559.15 and USD 659.79 based on the prices adopted by the CMED and WHO, respectively (Table 1). The differences in the cost of treatment with liposomal amphotericin B based on the CMED and WHO/MH were related solely to the cost of the drug, which was 97\% higher when CMED prices were used.

The amount of money reimbursed by the SUS to the health care services involved in the treatment of patients with VL using N-methylglucamine antimoniate was USD 172.50, regardless of whether the drug was administered intravenously or intramuscularly. The amounts of money reimbursed for treatment with amphotericin B deoxycholate and liposomal amphotericin B were USD 114.82 and USD 44.32, respectively (Table 2). 
TABLE 1

Estimated direct cost of drug regimens recommended by the Brazilian Ministry of Health for the treatment of patients diagnosed with visceral leishmaniasis.

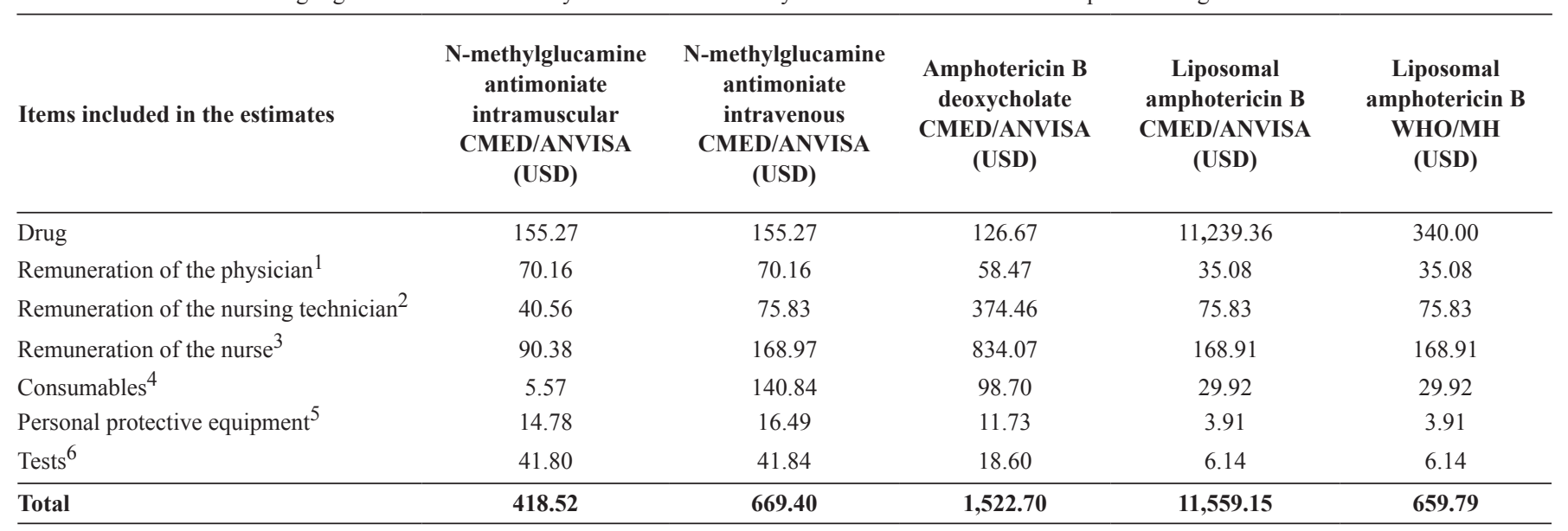

CMED: Câmara de Regulação do Mercado de Medicamentos; ANVISA: Agência Nacional de Vigilância Sanitária; WHO: World Health Organization; MH: Ministry of Health; USD: United States Dollars. ${ }^{\mathbf{1}}$ Monthly salary corresponding to a 40-hour work week: USD $2,806.37 ;{ }^{2}$ Monthly salary corresponding to 40 -hour work week: USD $564.55 ;{ }^{3}$ Monthly salary corresponding to a 40-hour work week: USD 1,257.27; ${ }^{4}$ Equipo, three-way stopcocks, dextrose solutions, Jelco catheters, hypodermic needles, plastic tubes for blood collection, cotton, and ethanol; ${ }^{5}$ Gloves and masks; ${ }^{6} \mathrm{~N}$-methylglucamine antimoniate: Urea and creatinine, $2 \times$ per week; electrocardiogram, blood count, alkaline phosphatase, aspartate transaminase, alanine transaminase, gamma-glutamyl transferase, amylase, bilirubin, albumin, and lipase, $1 \times$ per week. Amphotericin B deoxycholate and liposomal amphotericin B: Urea, potassium, magnesium, and creatinine, $2 \times$ per week; blood test, $1 \times$ per week.

TABLE 2

Refund amounts from the Public Health System to health services involved in treating patients with human visceral leishmaniasis.

Therapeutic regimen

$\mathrm{N}$-methylglucamine antimoniate $(20 \mathrm{mg} / \mathrm{kg} /$ day, 30 days $)$

Amphotericin B deoxycholate $(1 \mathrm{mg} / \mathrm{kg} /$ day, 21 days $)$

Liposomal amphotericin B (3mg/kg/day, 7 days)
Refund amount transferred to the health services involved in treatment (USD)

$114.82^{2}$

$44.32^{3}$

USD: United States Dollars. ${ }^{1}$ USD 44.32 (daily value for treatment for 2-10 days for a patient with a protozoal disease) + USD 128.17 (for 20 additional days). ${ }^{2}$ USD 44.32 (daily values for treatment for 2-10 days for a patient with a protozoal disease) + USD 70.49 (for 11 additional days). ${ }^{3}$ USD 44.32 (daily value for treatment for 2-10 days for a patient with a protozoal disease).

\section{DIscussion}

The social and economic impact of VL is significant because of the increased number of cases and rate of transmission in recent years ${ }^{18}$; in addition to the high morbidity and mortality associated with $\mathrm{VL}^{19,20}$. The effects of VL on the economy are evident because this disease mainly affects low-income populations, and the direct and indirect costs related to diagnosis and treatment are high ${ }^{21-23}$.

It is known that the drug regimens for VL cause serious side effects, increasing the rate of treatment discontinuation and the length of hospital stay ${ }^{17}$. In this context, performing economic analyses based on total treatment costs but not on drug prices alone, can provide useful results and assist managers with decisions making to provide cost-effective treatment options.

In this study, the direct cost of VL treatment using $\mathrm{N}$-methylglucamine antimoniate was estimated considering whether the drug was administered via the intramuscular or intravenous route. Although intramuscular treatment with $\mathrm{N}$-methylglucamine antimoniate was the least expensive (USD 418.52), drug administered via this route causes significant local pain. However, the clinical severity of VL often requires hospitalization, venous access, and increased patient tolerance of intravenous infusion, which is the most common route of administration.

A significant finding of this study was that the cost of intravenously administered N-methylglucamine antimoniate (USD 669.40) was similar to the cost of treatment with liposomal amphotericin B based on the values adopted by the WHO/MH (USD 659.79). Another important observation was that the cost of treatment with amphotericin B deoxycholate was also higher than that of treatment with subsidized liposomal amphotericin B by the $\mathrm{WHO} / \mathrm{MH}$, since the time of venous infusion raises substantially due to the costs required for nursing professionals. 
Given these findings and the recognized toxicity of antimoniate, a cost-effectiveness analysis is necessary to compare the available therapeutic alternatives for VL in Brazil.

Another relevant finding was the difference in the cost of treatment with liposomal amphotericin $\mathrm{B}$ based on the values adopted by the CMED/ANVISA (USD 11,559.15) and the WHO/MH (USD 659.79). This difference in the price between $\mathrm{CMED} / \mathrm{ANVISA}$ and $\mathrm{WHO} / \mathrm{MH}$ indicates that drug costs could be reduced if managers were to play a more influential role in negotiating prices.

A comparison of the currently allocated refund values with the direct costs for each treatment regimen indicates the need to evaluate and adjust the values of the SUS remuneration table. According to the Financial Sector of the Eduardo de Menezes Hospital, Hospital Foundation of the State of Minas Gerais, the refunds the hospital receives for treating a patient with VL are insufficient to cover all materials and services used and offered to the patient during the hospital stay.

Despite the limited number of economic studies focusing on the treatment of VL in Brazil, a few studies have evaluated the cost and cost-effectiveness of therapeutic strategies on the Indian subcontinent. However, the data presented are not comparable to the estimates found herein because of the methodological differences and specificities for each study, including the evaluation of different therapeutic regimens and variations in drug costs. Sundar et al. ${ }^{24}$ reported that the direct costs of treatment ranged from USD 490.00-845.00 when patients were treated with different drug regimens containing liposomal amphotericin B in Bihar, India. Additionally, the same location, the estimated direct cost of treatment with amphotericin B deoxycholate was USD $260.00^{25}$. Boelaert et al. ${ }^{26}$ estimated a direct cost of USD 150.00 for Glucantime ${ }^{\circledR}$ treatment in Sudan. Vanlerberghe et al. ${ }^{27}$ reported that the estimated direct costs of diagnosis using a rapid test and treatment with $\mathrm{N}$-methylglucamine antimoniate, amphotericin $\mathrm{B}$, and liposomal amphotericin $\mathrm{B}$ deoxycholate in various endemic areas were USD 120.10, USD 111.10, and USD 537.50, respectively.

In addition to the limited treatment options and high toxicity of drugs available for treating of VL, other factors that need to be considered include the reliance on imports and the concentration of production on sole suppliers. In 2002, Sanofi announced interest in discontinuing the production of Glucantime ${ }^{\circledR}$. After that, it was agreed that a technology transfer would be made from the pharmaceutical industry to the laboratories of the Brazilian Army. In 2004, Farmanguinhos synthesized antimony and produced batches of meglumine antimoniate, which was found to be as effective as the reference drug Glucantime ${ }^{\circledR}$. Farmanguinhos transferred the antimony production technology to the Indústrias Químicas Taubaté S/A, which later went bankrupt. However, Brazil can become autonomous in the production of meglumine antimoniate if Sanofi interrupts the production of Glucantime ${ }^{\circledR 9}$.

Amphotericin B and its lipid formulation represent $80 \%$ of the drugs that are commercially available for VL treatment in Brazil; however, the lipid formulations rely on imports from the United States. Despite the attractive properties of these drugs for the treatment of VL, including their leishmanicidal activity, relatively short treatment time, and good tolerability, their cost has remained high for most endemic countries. In 2010, owing to a WHO initiative, reduced prices for AmBisome ${ }^{\circledR}$ were negotiated with the manufacturer exclusively for the treatment of VL in developing countries. In 2013, a partnership for product development (PPD) with a focus on the production of liposomal amphotericin $\mathrm{B}$ and deoxycholate was signed with the Pharmaceutical Laboratory of Rio Grande do Sul (Laboratório Farmacêutico do Rio Grande do Sul) - a public institution - and the private laboratory Cristália, but the PPD was suspended in July 2015.

These results may help managers adopt therapeutic strategies for VL that reduce the direct costs of treatment in Brazil and improve patient safety. Studies evaluating the cost-effectiveness of current therapeutic strategies are under development and will strengthen decision making. This study indicates the economic feasibility of replacing N-methylglucamine antimoniate with liposomal amphotericin B if the value negotiated by the WHO and transferred to the $\mathrm{MH}$ is maintained.

\section{Acknowledgments}

We offer our deepest thanks to the institutions that provided technical support for the development and implementation of this study.

\section{Conflict of interest}

The authors declare that there is no conflict of interest.

\section{Financial support}

Conselho Nacional de Desenvolvimento Científico e Tecnológico 462199/2014-2. Centro de Pesquisas René Rachou, Fundação Oswaldo Cruz. Centro Federal de Educação Tecnológica de Minas Gerais.

\section{REFERENCES}

1. Word Health Organization (WHO). Leishmaniasis. Fact sheet 375. WHO. 2016a. http://www.who.int/mediacentre/factsheets/fs375/en. (Accessed 30 August 2016).

2. Ministério da Saúde (MS). Banco de dados do Sistema Único de Saúde (DATASUS). Leishmaniose Visceral. Casos confirmados no Sistema de Informação de Agravos de Notificação (SINAN). Brasília: MS; 2016. http://tabnet.datasus.gov.br/cgi/tabcgi. exe?sinannet/leishvi/bases/leishvbrnet.def (Accessed 29 February 2016).

3. Alvarenga DG, Escalda PM, Costa AS, Monreal MT. Visceral leishmaniasis: retrospective study on factors associated with lethality. Rev Soc Bras Med Trop. 2010;43(2):194-7.

4. Brustoloni YM, Cunha RV, Cônsolo LZ, Oliveira ALL, Dorval MEC, Oshiro ET. Treatment of visceral leishmaniasis in children in the Central-West Region of Brazil. Infection. 2010;38(4):261-67.

5. Campos Jr D. Clinical and epidemiological features of Kala-Azar in children. J Pediatr. 1995;71(5):261-5.

6. Romero GAS, Costa DL, Costa CHN, de Almeida RP, de Melo EV, de Carvalho SFG, et al. Efficacy and safety of available treatments for visceral leishmaniasis in Brazil: a multicenter, randomized, open label trial. PLoS Negl Trop Dis. 2017;11(6)e0005706. 
7. Silveira LJ, Rocha TJ, Ribeiro AS, Pedrosa CM. Historical series of patients with visceral leishmaniasis treated with meglumine antimoniate in a hospital for tropical diseases, Maceió-AL, Brazil. Rev Inst Med Trop. 2015;57(1):33-8.

8. Carvalho SFG, Borges LG. Utilização da associação de desoxicolato de anfotericina $b$ e antimoniato de meglumina no tratamento da leishmaniose visceral americana em crianças e adolescentes. IV Seminário de Pesquisa e Pós-Graduação e II Seminário de Iniciação Científica: Universidade Estadual de Montes Claros 2003.

9. Santos MA, Marques RC, Farias CA, Vasconcelos DM, Stewart $\mathrm{JM}$, Costa DL, et al. Predictors of an unsatisfactory response to pentavalent antimony in the treatment of American visceral leishmaniasis. Rev Soc Bras Med Trop. 2003;35(6):629-33.

10. Ministério da Saúde (MS). Secretaria de Vigilância em Saúde. Manual de Vigilância e Controle da Leishmaniose Visceral. Brasília: MS; 2014.

11. Berman JD, Badaro R, Thakur CP, Wasunna KM, Behbehani K, Davidson R, et al. Efficacy and safety of liposomal amphotericin B (AmBisome) for visceral leishmaniasis in endemic developing countries. Bull World Health Organ. 1998;76(1):25-32.

12. Ministério da Saúde (MS). Agência Nacional de Vigilância Sanitária (ANVISA). Câmara de Regulação do Mercado de MedicamentosCME. Brasília: MS; 2016b. http://portal.anvisa.gov.br/listas-deprecos (Accessed 16 August 2016).

13. World Health Organization (WHO); 2016b. http://www.who.int/ leishmaniasis/research/978_92_4_12_949_6_Annex6.pdf?ua=1 (Accessed 05 June 2016).

14. Marinho DS, Casa CNPR, Pereira CCA, Leite IC. Health economic evaluations of visceral leishmaniasis. treatments: a systematic review. PLoS Negl Trop. 2015;9(2):e0003527.

15. Prefeitura Municipal de Belo Horizonte. Diário Oficial do Município de Belo Horizonte, Minas Gerais. Poder Executivo. Secretaria Municipal do Governo. Lei no 10.898 , de 30 de Dezembro de 2015. http://portal6.pbh.gov.br/dom/iniciaEdicao.do?method=DetalheArt igo\&pk=1155788 (Accessed 16 August 2016).

16. Ministério da Saúde (MS). Sistema de Gerenciamento da Tabela de Procedimentos, Medicamentos e OPM do SUS-SIGTAP. Brasília: MS; 2016c. http://sigtap.datasus.gov.br/tabela-unificada/app/sec/ inicio.jsp. (Accessed 04 August 2016).
17. Ministério da Saúde (MS). Secretaria de Vigilância em Saúde. Leishmaniose visceral. Recomendações clínicas para redução da letalidade. Brasília: MS; 2011.

18. Conti RV, Moura Lane VF, Montebello L, Pinto Junior VL. Visceral leishmaniasis epidemiologic evolution in timeframes, based on demographic changes and scientific achievements in Brazil. J Vector Borne Dis. 2016;53(2):99-104.

19. Sarkari B, Naraki T, Ghatee MA, Abdolahi Khabisi S, Davami MH. Visceral leishmaniasis in southwestern Iran: a retrospective clinicohematological analysis of 380 consecutive hospitalized cases (1999-2014). PLoS One. 2016;11(3):e-0150406.

20. Driemeier M, Oliveira PA, Druzian AF, Lopes Brum LF, Pontes ER, Dorval ME, et al. Late diagnosis: a factor associated with death from visceral leishmaniasis in elderly patients. Pathog Glob Health. 2016;109(6):283-9.

21. Sarnoff R, Desai J, Desjeux P, Mittal A, Topno R, Ali Siddiqui $\mathrm{N}$, et al. The economic impact of visceral leishmaniasis on rural households in one endemic district of Bihar, India. Trop Med Int Heath. 2010; 2:42-9.

22. Sharma DA, Bern C, Varghese B, Chowdhury R, Haque R, Ali M, et al. The economic impact of visceral leishmaniasis on households in Bangladesh. Trop Med Int Heath. 2006;11(5):757-4.

23. Uranw S, Meheus F, Baltussen R, Rijal S, Boelaert M. The household costs of visceral leishmaniasis care in South-eastern Nepal. PLoS Negl Trop Dis. 2013;7(2):e-2062.

24. Sundar S, Goyal AK, More DK, Singh MK, Murray HW. Treatment of antimony-unresponsive Indian visceral leishmaniasis with ultrashort courses of amphotericin-B-lipid complex. Ann Trop Med Parasitol. 1998;92(7):755-64

25. Sundar S, Gupta LB, Rastogi V, Agrawal G, Murray HW. Shortcourse, cost-effective treatment with amphotericin B-fat emulsion cures visceral leishmaniasis. Trans R Soc Trop Med Hyg. 2000;94(2):200-4.

26. Boelaert M, Lynen L, Desjeux P, Van der Stuyft P. Costeffectiveness of competing diagnostic-therapeutic strategies for visceral leishmaniasis. Bull World Health Organ. 1999;77(8):667-74.

27. Vanlerberghe V, Diap G, Guerin PJ, Meheus F, Gerstl S, Van der Stuyft P, et al. Drug policy for visceral leishmaniasis: a costeffectiveness analysis. Trop Med Int Health. 2007;12(2):274-83. 